\title{
Does Experiencing Racialized Aggressions on Social Media Influence Perceptions About the Campus Racial Climate?
}

\author{
Heather T. Rowan-Kenyon ${ }^{1}$ (D) . Adam M. McCready ${ }^{2}$ (D) Nicole I. Barone ${ }^{1}$ (D) . \\ Ana M. Martínez Alemán ${ }^{1}$ (D)
}

Received: 8 November 2020 / Accepted: 12 October 2021 / Published online: 29 October 2021

(C) The Author(s), under exclusive licence to Springer Nature B.V. 2021

\begin{abstract}
The purpose of this study was to use structural equation modeling to examine how the experience of racialized aggressions on social media influenced the perceptions of campus racial climate for undergraduate students of color $(n=771)$. Findings suggest that students who experienced racialized aggressions on social media did report less positive perceptions of campus diversity climate. Given that in-person and online environments are growing evermore seamless for students, this has implications for campus climate and diversity programming.
\end{abstract}

Keywords Social media $\cdot$ Perceptions of campus climate $\cdot$ Racialized aggressions

\section{Introduction}

Social media play a central role in the college experience. Online platforms such as Facebook, Snapchat, Instagram and Twitter enable college students to compose campus culture and affect the ways in which they interact with one another (Martínez Alemán \& Wartman, 2009). Now fully integrated into college student life on campus, social media communication is an important element in how students experience campus life, and consequently, are a fundamental ingredient of campus climate today. Coincident with the assimilation of social media into campus life is the rise in online racism and harassment nationally (Pew Research Center, 2018, 2021). It is not surprising then, that researchers have begun to identify and examine online racism in higher education populations and settings. For example, Rogers (2016) highlighted the multitude of forms of discrimination and racial hate found on higher education online sites and mobile apps. Others have shed light on student experiences of racialized hate on social media that expose campus racism and its negative effects on students such as cultural paranoia and racial battle fatigue (Eschmann, 2020; Gin et al., 2017).

Heather T. Rowan-Kenyon

rowanken@bc.edu

1 Lynch School of Education and Human Development, Boston College, Chestnut Hill, MA, USA

2 Neag School of Education, University of Connecticut, Storrs, CT, USA 
Scholars have found that encountering instances of racism online has a particularly negative impact on students of color (Eschmann, 2020; Gin et al., 2017; Tynes et al., 2012, 2013). Recently, it has been shown that racialized aggressions have the potential to manifest at predominantly White institutions (Eschmann, 2020; Gin et al., 2017). Eschmann (2020) concluded that students of color directly connected racist messaging on an anonymous campus social media site to the campus racial climate. Rich qualitative work from Museus and Truong (2013) and Tynes and Markoe (2010) offer useful and valuable assessments of the contexts of social media on campus, providing interpretations of the effects of racist communication on these platforms. They point to the use of social media to communicate harmful stereotypes, to extend microaggressions to virtual behavior, and to direct harassment to particular groups of people. Referred to as "digital discourse" by Eschmann et al., (2020), these racist online communications can "normalize knowledge of the subtle mechanisms of structural racism and increase awareness of how covert acts can perpetuate racial inequality" (p. 11). Though Eschmann (2020) and others have begun to examine the impact of online racism on college climate, more work is needed to more fully understand the impact of online racism on students of color and how that online communication impacts their perceptions of campus climate. But like all qualitative studies, these studies have limited generalizability to the larger populations of college students of color, though their findings and conclusions can serve as the foundation for quantitative inquiries.

To expand our understanding of online racism and its effects on students of color and their perceptions of campus climate, and to fill the gap in the growing body of research literature on social media and campus climate, we chose to engage the phenomenon through quantitative methods. Through quantitative analysis, we were able to generalize from larger samples of students of color on multiple college campuses about the effects of online racism on their perceptions of campus climate. Consequently, the purpose of this study was to employ quantitative methods to examine how the experience of racism on social media by students of color influenced the perceptions of campus racial climate. The specific research questions were:

- Does the experience of racialized aggressions on social media affect students' perceptions of a positive racial climate on campus?

- What is the relationship between the experiences of racialized aggressions online, inperson experiences with racialized aggressions, ethnic identity, campus interactions and students' perceptions of the campus climate for diversity?

Campus climate research has focused primarily on students' in-person experiences of racialized aggressions, but we now know that these experiences also regularly occur online (Tynes et al., 2013). With nearly two-thirds of young adults experiencing racialized aggressions and more overt forms of harassment online (Pew Research Center, 2018), this specific line of inquiry is both timely and necessary given that this harassment has implications for how college students of color perceive their campus climate. It has become increasingly important to examine the linkages between the experiences of racism online and how online racist interactions impact the college experiences of students of color and their perceptions of its impact on campus climate.

In addition to filling a gap in the research literature, this study and its findings on the impact of social media on perceptions of campus climate can potentially deepen our scholarly conceptualization of campus climate. Though campus climate has been a focus of research for decades, it has been conceptually ambiguous, albeit increasingly wide-ranging (Hart \& Fellabaum, 2008). Since Peterson and Spencer (1990) put forth a conceptualization 
of campus climate as the aggregation of perceptions and atitudes held about campus life, scholars have sought to better reflect the ecology of campus climate by examining campus climate and racial and ethnic diversity (Hurtado, et al., 1998), LGBTQ (Parker III, 2021), and sexual assault (Moylan, et al., 2021), among other dimensions. These and other campus climate studies can inform and impact institutional practices. The findings from this study can serve to update practitioners' understanding of social media's role in campus climate, and how they can better attend to the effects of online racist communication on students of color.

\section{Theoretical Framework}

This work is grounded in Foucault's (1980) theory that knowledge and power (knowledge/ power) are discursive, thus they are indistinguishable from each other, are interchangeable constructs, and never independent of each other. Fundamentally, knowledge is an exercise of power, and power is an exercise of knowledge. Accepted and affirmed forms of knowledge constitute a society's "regimes of truth;" they compose its common beliefs and principles, and are a central feature of human behavior and relations in society. These 'truths' are endorsed through everyday relations that are all situated in relations of power, and may limit our behavior and experiences (Foucault, 1984). Discursive regimes of truth are an established way of communicating what can or cannot be thought and said about society and social relations. Media, education, and other institutions circulate discourses, that though never static, reflect the politics of societies.

Racism can be understood as a regime of truth or as a set of beliefs and opinions about racial hierarchy that is circulated through everyday relations conducted in all social spaces. As discursive, racism is normalized and can give psychological and emotional control to Whites that is not limited to acts of overt violence or discrimination (Delgado \& Stefancic, 2017). In schools and universities, racism is a discourse that is circulated through the curriculum, pedagogy, and other supporting social structures like the law. Through various media, racism is circulated through implicit and explicit text and images that communicate white hegemony. Racism is often communicated through racial slurs and hate speech, but also through words that have embedded racialized meanings in societies. For example, public use of terms like "inner city" and "thug" circulate a discourse of racist stereotypes consistent with a regime of truth about racial hierarchy in societies (Khoo, 2017; Lopez, 2016). On social media, racist speech, memes, and videos reach large audiences efficiently (Lamerichs, et al., 2018), and circulate "new and old racist practices" that are now standard on these media (Matamoros-Fernández \& Farkas, 2021, p. 22).

Given this, we view social media as a tool that can circulate a discourse of racism (racist knowledge/power) that, like all discourses, regulate or "discipline" the thinking and behavior of users (Foucault, 1975). Whether deliberately intended to harm (e.g., referring to black students as "monkeys" in the cafeteria) or unintentionally damaging (e.g., insensitive jokes), interactive internet-based social media can serve as a discursive means to circulate explicit or implicit racism (Gin, et al., 2017).

We utilize the racist aggression framework proposed by Minikel-Lacoque (2012), who challenged aspects of Sue and colleagues' (2007) microaggression work but extended it to intentional acts of racism, as well as operationalized racism as a discursive element of social media communication. Minkel-Lacoque made the argument that campus racism in all its forms should be understood as "racialized aggression," and should include those 
found online because they are typically intentional and conscious acts. She challenged the use of the adjective "micro" to describe online "blatant, intentional expressions of hate" as a discursive act that serves to "empower the perpetrators" (p. 455). To characterize racist acts as "micro," argued Minikel-Lacoque, enables those with more racial power (Whites) to conclude that racist posts are tolerable and acceptable (p. 455).

In Sue and et al.'s (2007) taxonomy of microaggressions, intentional and unintentional racist aggressions are verbal and behavioral manifestations of the discourse of racism. Racial insults and slights are further distinguished as microinsults (that are often unconscious), microassaults (that are often conscious), and microinvalidations (often unconscious). All of these microaggressions are connected to macro-level environmental microaggressions such as racial assaults, and "insults and invalidations which are manifested on systemic and environmental levels" (p. 278). Racial assaults, then, as "systemic" can be understood as one discursive materialization of racism. Though Sue and et al., (2007) did not consider social media technologies specifically in their examples of microaggressions, Minikel-Lacoque (2012) updated this work to include online posts. Such posts can be unconscious comments that "fit with the original notion of racial microaggressions" (p. 452), but can also be "intentional expressions of hate" (p. 452). Further, noted MinikelLacoque, online social media give users a distinctive stage where "traditionally covert and overt" racist discourse are combined (p. 453).

These online expressions of hate, argued Minikel-Lacoque (2012), should be "understood as "racialized aggressions" (p. 455), and not "microaggressions." This call for a rhetorical change in the language used to describe these expressions is an argument for the power of discourse. Discourse is constructed (in part) by rhetorical language in such a way as to exert power. A system of representation, discourse leverages rhetorical language to produce an effect on individuals (Foucault, 1980). Though not directly attributing her analysis to a Foucauldian conceptualization of the discursive power of rhetorical language, Minikel-Lacoque essentially makes the case that racism is a discourse and points to social media as a discursive tool. For this reason, we use the term "racialized aggressions" to signify the discursive nature of racism online.

\section{Review of the Literature}

\section{Campus Climate and Racial Aggressions}

Racialized aggressions affect college students' educational experiences, mental health, and general well-being. These verbal attacks incite stress, anxiety and depression among college students with marginalized and minoritized identities (McCready et al., 2021; Nadal, 2008; Nadal et al., 2015; Sue et al, 2008). Further, these aggressions negatively affect students on a number of higher education outcomes, including resilience and academic performance (Franklin et al., 2014; Nadal et al., 2015; Smith et al., 2006, 2007). These experiences also impact students' perceptions of campus racial climate (Smith et al., 2007). The racial climate, particularly at Predominantly White Institutions (PWIs), may have adverse effects on students' academic, social, and interpersonal experiences (Fischer, 2007; Yosso et al., 2009).

A growing body of literature demonstrates the effects that campus racial climate has on the college student experience, particularly on the academic and social experiences of students of color. Milem et al. (2005) asserted that there are several institutional dimensions 
that affect how students experience campus racial climate: historical legacy, compositional diversity, the psychological dimensions of climate (e.g., perception of and experiences with racism, discrimination, and prejudice), behavioral dimensions, and the organizational and structural dimensions of climate.

Studies have shown that for students of color, direct experiences with racism and discrimination negatively impact their perception of the campus racial climate, which in turn impacts persistence (Johnson et al., 2014; Wells \& Horn, 2015), satisfaction (Hurtado \& Carter, 1997; Lin et al., 2019), perception of an institution's commitment to diversity efforts (Griffin et al., 2016; Hurtado, 1992; Wells \& Horn, 2015), and social preferences (George Mwangi et al., 2018b). Further, direct experience with racism and microaggressions often creates additional stress for students of color and results in feelings of marginalization and isolation (Solórzano et al., 2000).

A number of studies have disaggregated perceptions of campus racial climate by race and found that students of color perceive the campus racial climate more negatively than their White peers (Cabrera et al., 1999; Rankin \& Reason, 2005; Reid \& Radhakrishnan, 2003). Hurtado (1992) found that White students are less likely to think critically about their racial background, and recent research also established that White students are less likely to perceive racial tension and conflict (Hurtado et al., 2015). Taken together, these studies indicate that direct and indirect experiences with racism and racist interactions led to feelings of isolation, marginalization, and discouragement among students of color, as well as negative perceptions of the campus racial climate (Griffin et al., 2016; Harper \& Hurtado, 2007).

Scholars have established that students attending PWIs from minoritized racial and ethnic groups report experiences with racial discrimination, microaggressions, and stereotypes (Hurtado et al., 1996, 2015; Suarez-Balcazar et al., 2003). For example, Yosso et al. (2009) found that Latina/o students in their study experienced racial microaggressions and jokes, and expressed feelings of being perceived differently on campus. More recently, George Mwangi et al. (2018a) found that Black students felt that their race was associated with fear among their non-Black peers, and Roberston et al. (2016) identified that Latina/o students' experiences with on-campus racism affected their perceptions of the hospitalibleness of their campus community.

Compositional diversity has also been shown to affect students' satisfaction with their college experience, and perception of an institution's commitment to diversity efforts (Griffin et al., 2016; Hurtado, 1992; Wells \& Horn, 2015). Wells and Horn (2015) found that Asian American students at a racially diverse institution reported positive perceptions of campus culture when cultural congruence, or the extent students' ethnic culture was reflected in the broader campus culture, was part of the campus climate.

\section{Online Racism}

While much of the work on perceptions of campus racial climate has focused on in-person interactions, the growth of social media cannot be ignored. Worldwide, social media are a principal communication tool for social and political discourse today, and are a site in which "new and old racist practices increasingly take place" (Matamoros-Fernandez \& Farkas, 2021, p. 22). In the U.S., the Pew Research Center reported that though the overall prevalence of online hate has not increased since 2017, online harassment has intensified since then (Pew, 2021). Additionally, Pew (2021) reported that 54\% of Blacks and $47 \%$ of Hispanics reported their harassment as racially or ethnically focused. Research on various 
age groups (including those that comprise traditional campus populations) has shown that online racism is perceived as a form of interpersonal discrimination (Keum \& Miller, 2019). Online hate is quite frequent on social media, with an estimated 10,000 racist English-language utterances daily on Twitter (Bartlett, et al., 2014). Recent research on online anti-Asian hate during the COVID-19 pandemic finds online hate commonplace and extensive, much more so than counter narratives of racial equality and inclusion (Ziems, et al., 2020). Social network analysis has shown how anti-Muslim groups rely their Facebook pages to communicate and propagate negative stereotypes of Muslims as violent enemies worthy of retributional violence (Squire, 2019).

Though the literature on campus racial climate as it pertains to students' in-person experiences is rich and deep, research on racialized aggressions on social media is relatively recent but increasing. As social media provides students of color with "counterspaces" to online racism (George Mwangi, et al., 2018b), encountering racialized hostility on social media while on campus is increasingly a challenge (Rowan-Kenyon et al., 2016). Negative and antagonistic anonymous posts on students' social media have enabled intimidation and harassment on the basis of gender, sexuality, race and ethnicity (Black, et al., 2016). Exposure to online racialized aggression has negatively impacted students' of color mental health (McCready et al., 2021), and increased stress expressions (Saha, et al., 2019). An examination of microagressions online sugggested that they impact Indigenous students negatively (Clark, et al., 2011), and though not specifically focused on racialized agressions online, Tynes, et al. (2013) found a strong relationship between online discrimination and the perception of campus climate, and urged researchers to give more attention to negative racist interactions online.

\section{Other Factors That Influence Perceptions of Campus Climate}

It is important to consider additional factors that may influence student perceptions of campus racial climate. Researchers have considered how the development of a person's racial or ethnic identity, and their interactions with others on the campus influence their perceptions of the campus racial climate.

\section{Racial/ethnic Identity Development}

Scholars who have examined the relationship between racial or ethnic identity and campus racial climate found that experiences with racism, racial prejudice, and racial microaggressions negatively impact the social and academic experiences of students of color (Cabrera et al., 1999; Griffin et al., 2016; Harper \& Hurtado, 2007). The impact of racial and ethnic identity, along with the perceptions of racial diversity on campus have implications for how students of color view their campus climate.

Researchers have consistently demonstrated that students' racial and ethnic identities are inextricably tied to how they perceive and experience campus racial climates at PWIs. Examining Asian American and Pacific Islander (AAPI) students and their perceptions of campus climate at a PWI, Nguyen, et al. (2018) corroborated the claim that negative racialized experiences correspond with AAPI students' feeling detached and irrelevant on campus. Grounded in the research literature on Black students' negative perceptions of campus climate and its relationship due to subtle and overt racism and racial hostility, George Mwangi and et al.'s (2018a) study on Black students' perceptions of campus climate and 
its relationship to US racial climate makes clear that how students perceive campus climate is inextricably linked to their racial/ethnic identities. Black students' negative perceptions of campus climate, for example, is "contextualized by their racial identities when (as Black bodies) they encounter tension-filled interactions with campus police" (pp. 463-464).

In the research literature on racial and ethnic identity development, Phinney and Alipuria's (1990) foundational work on ethnic identity as a key aspect to identity development in college students, suggested that students of color do have a particular commitment to developing that aspect of their identities. Later work by Atkinson and colleagues (1998), and Sue and Sue (2013) proposed stages of ethnic or cultural identity development that included phases or periods in which students of color are introspective and gain greater awareness of the complexities of race and ethnicity in society. That arc of ethnic identity development also maps onto research that links an increase in ethnic identity awareness to experience with multicultural education (Ortiz \& Rhoads, 2000), and with opportunities to critically assess social knowledge about ethnic identity (Torres, 2003). In sum, researchers are in agreement that college students' ethnic identity development appears to be closely tied to their cognitive development in college, and that students' exposure to critical accounts of racial and ethnic "social knowledge" appears to impact their ethnic identity development (Torres \& Baxter-Magolda, 2004).

Ethnic and racial identity development is also affected by components of campus climate such as curricular exposure and opportunities to examine their racial/ethnic identities (Ortiz \& Rhoads, 2000; Torres, 2003). For example, Chavous, et al. (2017) concluded that students' "developmental and contextual transition periods" (p. 14) can correlate with changes in their assumptions about and acceptance of their racial identity. Their development in this area can also influence their perceptions during college. Bonafacio et al. (2018), found that a student's ethnic identity and exposure to racial microaggressions influenced their career self-efficacy and anticipated career outcomes. Eccles and colleagues (2006), also found that a student's development related to ethnic identity mitigated the experience of racist actions on the student's self-concept and school achievement. It also stands to reason that students' racial and ethnic identity development is linked to and may affect their perceptions of the campus diversity climate.

\section{Campus Interactions}

Students' in-person interactions are also important to consider in examining campus climate and racialized aggressions online. Foundational scholarship on campus climate and diversity by Hurtado and et al., (1998) demonstrated that beyond structural diversity, attitudinal and behavioral attributes or how particular groups of individuals "feel" about and relate to one another" (p. 296) are key to consider when focusing on campus racial climate. Researchers have concluded that college students' development and academic success is correlated with their interactions with faculty (Lau, 2003; Mayhew et al., 2016). Foundational scholarship has asserted that "validation" by faculty and staff is a key component to marginalized students' academic success and feelings of belonging in college (Rendon, 1994). Rendon's validation theory provided a model for researching the many ways in which faculty and staff (as well as other campus members) can intentionally affirm marginalized students' sense of belonging, effectively suggesting that the quality or characteristic of faculty and staff interactions with students of color are critical to their campus experience. Linares and Muñoz (2011) updated this foundational work suggesting, among other considerations, that researchers take up the 
task of "providing more specific examples of academic and interpersonal validation in and out of the classroom context" (p. 27). More germane to our study, recent research has focused more specifically on the connection between students' interactions with faculty and their perceptions of the campus diversity climate. Parker \& Troilian (2020) identified both positive and negative effects of student-faculty interactions, student perceptions of faculty, and campus diversity climate, and suggested that "students' interactions with and perceptions of faculty members in college are associated with student perceptions of the climate for diversity on campus" (p. 341). Further, Parker and Trolian concluded "that it may be the type and context of the experiences that students have with faculty that matter in fostering students' perceptions of an inclusive campus climate" (p. 341). Kim and Lundberg (2016) pointed out that there are disparities in the effects of student-faculty interactions between students of color and White students, and needs to be examined further.

The current study moves forward Tynes and et al.'s (2013) recommendation to further examine negative racist interactions online and build on prior qualitative work (e.g. Gin et al., 2017; Minikel-Lacocque, 2012; Tynes et al., 2013) related to students' experiences. Based on the experience of students of color at PWIs, and their perceptions of the campus racial climate, we hypothesize that by experiencing racialized aggressions on social media, students are likely to report a less positive perception of campus climate. We also expect that racial and ethnic identity, campus interactions, and in-person experiences with racism will influence the perceptions of campus climate for diversity.

\section{Method}

\section{Sample and Data Sources}

The present study used a multi-campus sample to explore the influence of experiencing racialized aggressions on social media on positive perceptions of campus climate. Participants were 771 undergraduate students of color from five four-year PWIs in the United States who completed a 152-item web-based survey between spring 2018 and spring 2019. Four sites are private universities located in the northeast, and one is a public research university in the south. Two of these institutions had a business focus, one was a liberal arts college, and two were research universities. We recruited institutions through a variety of ways including an association listserv for Higher Education assessment professionals, and personal outreach to student affairs professionals responsible for assessment. Please see Table 5 in Appendix A for additional information about the institutions.

All full-time undergraduate students who identified as students of color were invited to participate in the study at each institution. Participants identified with one or more of the minoritized racial or ethnic identities defined by the United States Office of Management and Budget (2016) and were 18 years of age or older. Over half of the sample identified as Black or African American (53.2\%). Of the remaining participants, 20.4\% identified as Asian, $10.6 \%$ identified as multiracial or multiethnic, $1.3 \%$ identified as Middle-Eastern or North African, $0.9 \%$ identified as Native-American or Native Alaskan, $0.4 \%$ identified as Native Hawaiian or Pacific Islander, and $0.3 \%$ identified with other racial or ethnic identified. Asked separately, $18.8 \%$ of the sample identified as Hispanic, Latino/a or Spanishorigin. Other demographic information about the sample can be found in Table 1. 
Table 1 Participant characteristics

\begin{tabular}{lr}
\hline Characteristic & \% of Participants \\
\hline Gender & \\
Female & 70.7 \\
Male & 28.1 \\
Gender-queer & 1.0 \\
Other & 0.1 \\
Race/Ethnicity & \\
African American/Black & 53.2 \\
Asian & 20.4 \\
Hispanic/Latino/Spanish origin & 18.8 \\
Middle Eastern/North African & 1.3 \\
Multiracial/Multiethnic & 10.6 \\
Native American/Native Alaskan & 0.9 \\
Native Hawaiian/Pacific Islander & 0.4 \\
Other race or ethnicity & 0.3 \\
Class year & \\
First year & 24.3 \\
Second year & 25.0 \\
Third year & 22.1 \\
Fourth year & 22.6 \\
Fifth year or greater & 6.0 \\
Campus Residence & 3.8 \\
On-campus & 6.1 \\
Off-campus & 1.4 \\
Commuter & \\
Parent/Primary Caregiver Education & 3.8 \\
Attended high school & \\
High school graduate & 20.2 \\
Attended college & 20.6 \\
Bachelor's & 29.2 \\
Attended graduate school & 32.4 \\
Master's or above & \\
Unsure & \\
United States residency status & \\
Citizen & \\
International student & \\
Permanent resident & \\
Other status & \\
\hline & \\
&
\end{tabular}

\section{Measures}

We utilized the Racist Aggressions on Social Media Survey to collect data for this study. We (Rowan-Kenyon et al., 2021) developed this instrument by adapting and validating psychosocial metrics and campus experiences scales, and the encounters to broaden and deepen our understanding of the impact of online racist aggressions on students of color. 
We adapted scales known for their strong psychometric properties, to try to capture interactions with social media. We piloted the instrument (including conducting cognitive interviews) with a sample of students of color (Rowan-Kenyon et al., 2021).

Primary dependent variable. The dependent variable for our study is an adaptation of the Positive Perceptions about the Campus Diversity Climate Scale (PPDC) (Inkelas et al., 2006). This seven-item measure $(\alpha=0.85)$ describes a participant's level of agreement about the occurrence of cross-racial or ethnic interactions with peers, faculty and administrators, and their institutional commitment to the success of students of color (e.g., "There is a culture of trust and respect between students of different racial/ethnic origins"). See Table 2 for more information about the PPDC and the scales included in the study. This seven item measure describes respondents' level of agreement with items such as (a) occurrence of cross-racial interaction on campus, (b) the common occurrence of cross-racial friendships, (c) presence of a culture of respect among students of different racial/ethnic origins, (d) campus commitment to the success of students of color, (e) students of different racial/ethnic origins communicate well with one another, (f) how professors respect students of color, and $(\mathrm{g})$ the level of trust between students of color and administrators.

Other endogenous and exogenous variables. We measured daily encounters with racism on social media with the five-item Everyday Discrimination Scale Social Media (EDS-SM; $\alpha=0.84$ ). We adapted the EDS-SM from the revised-EDS developed by Stucky et al. (2011). Stucky and colleagues (2011) revised the original nine-item EDS developed by Williams et al., (1997). The EDS and revised-EDS are frequently used scales that an individual's daily encounters with discrimination, and the scales are known for their strong psychometric properties.

In addition to encounters with racism on social media, we adapted versions of Harrell's (1997) Racism and Life Experiences (RaLES)—Racism Experiences type subscale to reflect students' encounters with on-campus racism at their colleges or universities (see Table 2). Scholars have relied on the RaLES to examine the consequences associated with perceived racism (e.g., Sellers \& Shelton, 2003). The adapted 10-item scale $(\alpha=0.94)$ measures the frequency in which an individual endures a particular racialized aggression while on their campus. The internal consistency of the full scale has been found to routinely be good or excellent, with Cronbach's alphas exceeding 0.83 (Bond et al., 2007).

Because prior research (e.g., Mayhew et al., 2016), found that student interactions with faculty and staff at an institution influences student outcomes, we measured the quality of student interactions with various faculty and staff members at their institution. Participants rated their interactions with faculty, academic advisors, student services staff, multicultural affairs staff and other administrative staff and offices from poor (1) to excellent (7). We found the scale to have good internal consistency, $\alpha=0.87$.

The only exogenous variable included in the model was sense of ethnic identity, as measured with the six-item Multigroup Ethnic Identity Measure-Revised (MEIM-R; Phinney \& Ong, 2007). The MEIM-R measures an individual's internalized commitment to,

Table 2 Descriptive statistics and internal reliabilities for survey scales

\begin{tabular}{lccc}
\hline Scale & N Items & M (SD) & $\alpha$ \\
\hline Positive perceptions of diversity climate & 7 & $25.73(5.30)$ & 0.85 \\
Everyday discrimination-social media & 8 & $4.76(5.52)$ & 0.84 \\
Encounters with racism on campus & 10 & $10.86(9.67)$ & 0.94 \\
Ethnic identity & 6 & $3.10(0.68)$ & 0.90 \\
Campus interactions & 5 & $26.39(7.04)$ & 0.87 \\
\hline
\end{tabular}


and exploration of, ethnic identity. An overwhelming majority of researchers who have measured ethnic identity have utilized the MEIM-R or its predecessor, the MEIM developed by Phinney (1992) (e.g., Yoon, 2011). The 6-item MEIM-R is more parsimonious than the full 20 -item version, and it has been found to have better construct validity than the original (Phinney \& Ong, 2007). Phinney and Ong (2007) identified that the MEIM-R has good internal consistency, and another study found that the scale had strong psychometric properties among college students (Yoon, 2011). We found the scale to have good internal consistency, $\alpha=0.90$.

\section{Analyses}

We used SPSS Amos statistical software to analyze covariance matrices of the data with maximum likelihood estimation. Relying on structural equation modeling (SEM), we created two models to examine relationships among the variables. The latent variables in the initial model were PPDC, EDS-SM, campus interactions, and ethnic identity. The model included direct paths from all of the variables to PPDC. We included paths from ethnic identity to each of the other variables. Bootstrapping was performed on 500 samples with a $95 \%$ confidence interval to examine the statistical significance of the indirect, direct and total effects of the paths in the models.

The latent variables in the final model were PPDC, EDS-SM, campus interactions, encounters with racism on campus, and ethnic identity. The model included direct paths from all of the variables to PPDC. Like the initial model, we included paths from ethnic identity to each of the other variables. Because the measures of encounters with racism are endogenous variables, we included correlational paths from the disturbances of EDS-SM to encounters with racism on campus.

We relied on confirmatory factor analysis to examine the measurement model before creating the final SEM model. The fit statistics were excellent. The confirmatory fit index (CFI) of 0.92 , the root mean square error of approximation (RMSEA) of 0.06 and $\chi^{2} / d f$ of 3.42 indicate a good model fit. The good-of-fit indices for the final SEM model were also excellent, $\mathrm{CFI}=0.92$, $\mathrm{RMSEA}=0.06$, and $\chi^{2} / d f$ of 3.42 .

\section{Limitations}

It is important to acknowledge the limitations of the study. Without having additional context, it is not possible to quantify or qualify students' encounters with racialized aggressions, perceptions of campus diversity climates, sense of ethnic identity, or interactions with faculty, staff, or administration. While the cross-sectional SEM design employed in the study allowed us to examine previously unexplored relationships between encounters of racism on social media and other variables of interest and make rigorous statistical inferences, the findings do not infer causality. However, we do hypothesize causal relationships. Additional research is needed to make stronger inferences about the relationships of the variables, and scholars should consider longitudinal designs for future studies. While our design is novel, we did not examine for measurement invariance for covariates like racial identity. Future research should test for the invariance of the constructs included in our study.

We recognize that student learning and development is complex (Patton et al., 2016), and that no single model can fully capture each student's experience. The paths in our SEM 


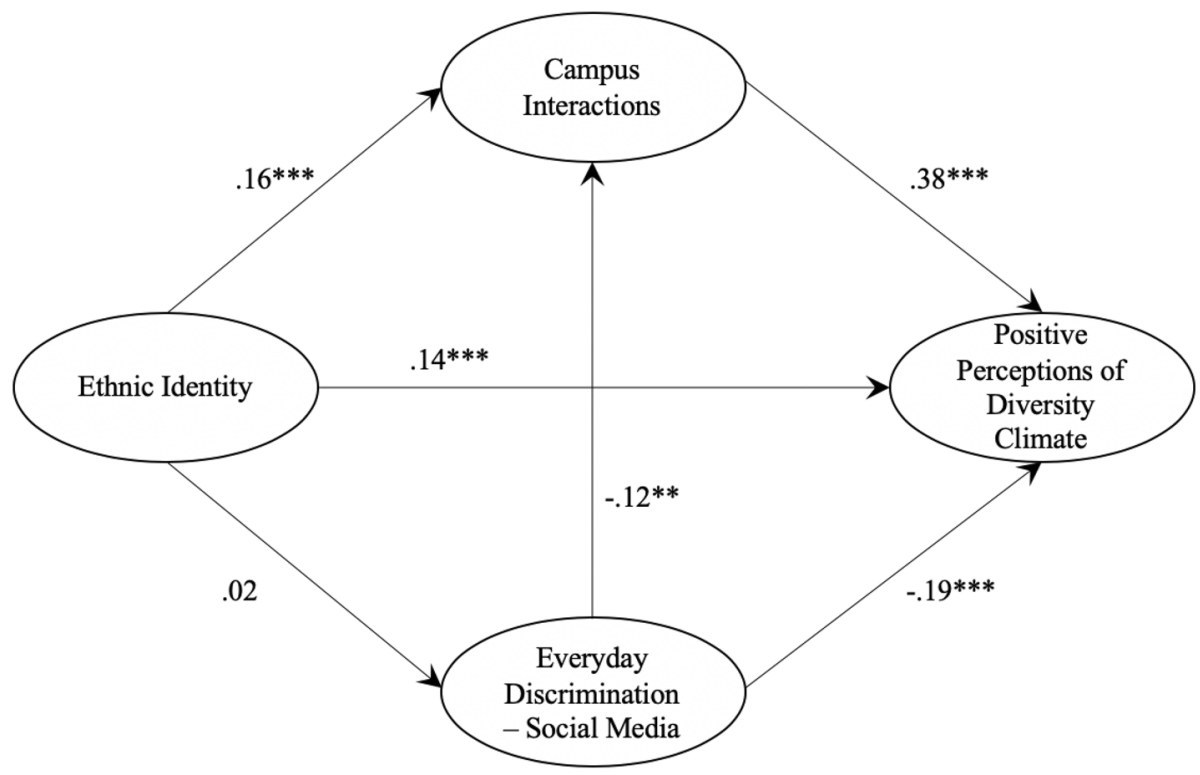

Fig. 1 Standardized coefficients for initial structural equation model predicting positive perceptions of diversity climate without encounters with racism on campus. For simplicity of presentation, disturbances to latent factors with the exception of the pair for the correlational path are not shown. Bi-directional arrows indicate a correlational path. "D" signifies a disturbance. $* p<0.05, * * p<0.01$, ***p $p 0.001$

models may not represent every students' of color responses to encounters of racialized aggressions on social media or in-person, or how the constructs of interest in this study relate to their perceptions of campus diversity climates. However, we are hopeful that our study will motivate scholars to continue to examine and explore how encounters with racialized aggressions on social media affect the college experience of students of color.

Finally, the majority of participants in our sample $(66.8 \%)$ were from the public research university located in the south. The relationships among the variables might vary across institutions, but the sample is too small to perform multi-group SEM analyses. Future research should explore if these relationships vary between institutions.

\section{Results}

In response to our first research question, EDS-SM was found to have a statistically significant negative relationship with PPDC in the initial SEM model $(\beta=-0.19, p<0.001$; see Fig. 1). As shown in Fig. 2, the disturbances between EDS-SM and encounters with racism on campus were positively correlated in the final SEM model $(\beta=0.48, p<0.001)$, suggesting a positive association between in-person and online encounters with racial hostility. While EDS-SM alone was not found to have a statistically significant relationship with PPDC in the final model $(\beta=-0.05, p=0.22)$, encounters with racism on campus negatively related to the outcome $(\beta=-0.30, p<0.001)$. This finding indicates that on-campus encounters with racism mediates the relationship between EDS-SM and PPDC. 


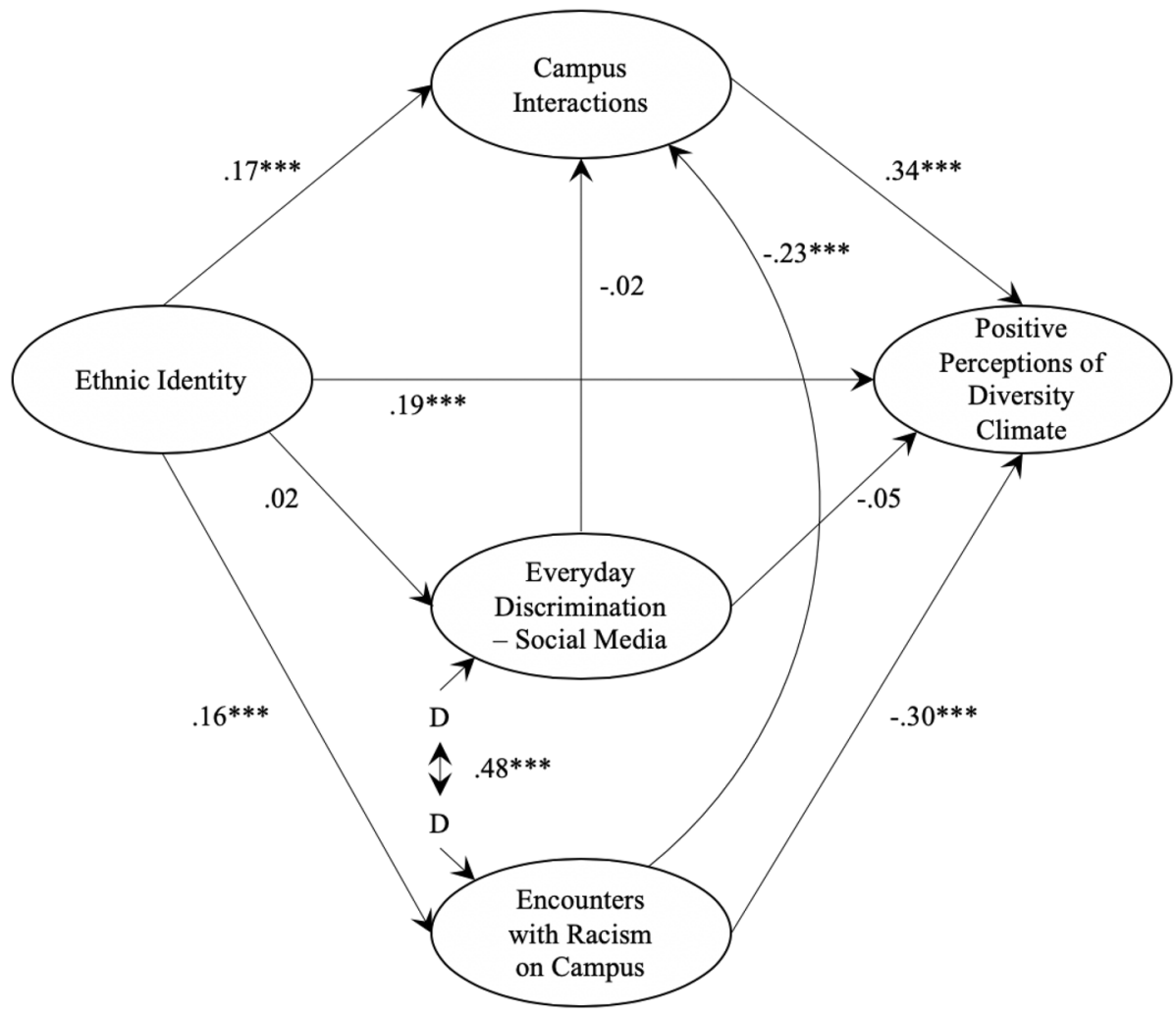

Fig. 2 Standardized coefficients for initial structural equation model predicting positive perceptions of diversity climate including encounters with racism on campus. For simplicity of presentation, disturbances to latent factors with the exception of the pair for the correlational path are not shown. Bi-directional arrows indicate a correlational path. " $\mathrm{D}$ " signifies a disturbance. $* p<0.05, * * p<0.01, * * * p<0.001$

We also examined the relationships between EDS-SM, encounters with racism on campus, campus interactions, ethnic identity, and PPDC. In the initial SEM model, EDS-SM was inversely associated with campus interactions $(\beta=-0.12, p<0.01)$. We found that ethnic identity was positively related to campus interactions $(\beta=0.14, p<0.001)$ and PPDC $(\beta=0.16 p<0.01)$. Campus interactions was associated with PPDC $(\beta=0.38, p<0.001)$. We did not find a statistically significant relationship between ethnic identity and EDS-SM.

We also found several indirect effects were significant in the initial model (see Table 3 ). EDS-SM had a negative indirect effect on PPDC $(\beta=-0.05, p<0.01)$. Ethnic identity had a positive indirect effect on PPDC $(\beta=0.05, p=0.01)$. In addition, the total effects to PPDC for EDS-SM $(\beta=-0.23, p<0.01)$, ethnic identity $(\beta=-0.20, p<0.01$, and campus interactions $(\beta=0.38, p<0.01)$ were found to be statistically significant.

In the final SEM model that included on-campus encounters with racism, EDS-SM was also no longer found to be associated with campus interactions with the inclusion of oncampus encounters with racism in the final model $(\beta=-0.02, p=0.64)$. This finding indicates that on-campus encounters with racism mediates the relationship between EDS-SM and campus interactions. Encounters with racism on campus was associated with campus interactions $(\beta=-0.23, p<0.001)$. Like the initial model, ethnic identity was associated 
Table 3 Indirect and total effects for initial structural equation modeling analysis

\begin{tabular}{|c|c|c|c|c|c|}
\hline & \multicolumn{2}{|l|}{ Indirect } & \multicolumn{3}{|l|}{ Total } \\
\hline & $B(S E)$ & $\beta$ & $B(S E)$ & $\beta$ & $R^{2}$ \\
\hline Positive perceptions of diversity climate & & & & & 0.24 \\
\hline Everyday discrimination-social media & $-0.01 * *(0.01)$ & -0.05 & $-0.04 * *(0.01)$ & -0.23 & \\
\hline Ethnic identity & $0.01 *(0.01)$ & 0.05 & $0.06 * *(0.02)$ & 0.20 & \\
\hline Campus interactions & & & $0.07 * *(0.02)$ & 0.38 & \\
\hline Campus Interactions & & & & & 0.03 \\
\hline Everyday discrimination-social media & & & $-0.12 * *(0.04)$ & -0.12 & \\
\hline Ethnic identity & $<-0.01(0.01)$ & $<-0.01$ & $0.22 * *(0.08)$ & 0.13 & \\
\hline Everyday discrimination-social media & & & & & 0.00 \\
\hline Ethnic identity & & & $0.03(0.06)$ & 0.02 & \\
\hline
\end{tabular}

$* * p<.01 ; * p<.05$

with PPDC $(\beta=0.19, p<0.001)$, and campus interactions $(\beta=0.17, p<0.001)$, but did not have a statistically significant relationship with $\operatorname{EDS}-\operatorname{SM}(\beta=0.02, p=0.63)$. We also found that ethnic identity was associated with encounters with racism on campus $(\beta=0.16$, $p<0.001)$. Consistent with the initial model, campus interactions had a statistically significant relationship with PPDC $(\beta=0.34, p<0.001)$.

A couple of indirect effects were statistically significant in the final SEM model (see Table 4). Encounters with racism on campus had a negative indirect effect on PPDC $(\beta=-0.08, p<0.01)$. These encounters appear to dampen the value of a student's interactions with faculty and staff on their perceptions of the campus diversity climate. Ethnic identity had a negative indirect effect on campus interactions $(\beta=-0.04, p<0.01)$, and students with a stronger sense of ethnic identity may have lower quality interactions

Table 4 Indirect and total effects for final structural equation modeling analysis

\begin{tabular}{|c|c|c|c|c|c|}
\hline & \multicolumn{2}{|l|}{ Indirect } & \multicolumn{3}{|l|}{ Total } \\
\hline & $B(S E)$ & $\beta$ & $B(S E)$ & $\beta$ & $R^{2}$ \\
\hline Positive perceptions of diversity climate & & & & & 0.30 \\
\hline Everyday discrimination-social media & $<-0.01(<0.01)$ & -0.01 & $-0.01(.01)$ & -0.06 & \\
\hline Encounters with racism on campus & $-0.02 * *(0.01)$ & -.08 & $-0.30 * *(0.03)$ & -0.38 & \\
\hline Ethnic identity & $<-.01(0.01)$ & $<-0.01$ & $0.06 * *(0.02)$ & 0.18 & \\
\hline Campus interactions & & & $0.07 * *(0.02)$ & 0.34 & \\
\hline Campus interactions & & & & & 0.07 \\
\hline Everyday discrimination-social media & & & $-0.02(0.05)$ & -0.02 & \\
\hline Encounters with racism on campus & & & $-0.30 * *(0.07)$ & -0.23 & \\
\hline Ethnic identity & $-0.06 * *(0.02)$ & -0.04 & $0.22 *(0.08)$ & 0.14 & \\
\hline Everyday discrimination-social media & & & & & 0.00 \\
\hline Ethnic identity & & & $0.03(0.07)$ & 0.02 & \\
\hline Encounters with racism on campus & & & & & 0.03 \\
\hline Ethnic identity & & & $0.19 *(0.05)$ & 0.16 & \\
\hline
\end{tabular}

$* * p<.01 ; * p<.05$ 
with faculty or staff after experiencing racism on social media or on-campus. Several total effects were statistically significant in the final SEM model. The total effects of encounters with racism on campus on PPDC $(\beta=-0.47, p<0.01)$, and campus interactions $(\beta=-0.32$, $p=0.01$ ) were statistically significant. Similarly, total effects of ethnic identity on PPDC $(\beta=0.08, p<0.01)$, encounters with racism on campus $(\beta=0.08, p=0.01)$, and campus interactions $(\beta=0.04, p=0.01)$ were statistically significant. The total effects of campus interactions on PPDC $(\beta=0.25, p<0.01)$ were also statistically significant. It is important to note that the indirect and total effects of EDS-SM on PPDC were no longer significant upon the inclusion of on-campus encounters with racism in the final model. These findings indicate that on-campus encounters with racism mediates all the effects of racialized aggressions on social media on student's perceptions of campus diversity climate.

\section{Discussion}

We hypothesized that by experiencing racialized aggressions on social media students of color are likely to report less positive perceptions of campus climate for diversity. We also expected that ethnic identity, campus interactions, and in-person experiences with racism will directly and indirectly influence the perceptions of campus climate for diversity. The results from this study are mixed.

In our initial model, students who experienced racialized aggressions on social media did report less positive perceptions of campus diversity climate. However, when in-person experiences with racism were also included, online racialized aggressions were no longer significant. We hypothesize that in-person experiences with racism overshadow racist behavior online, though given that covariance between RALES and EDS-SM is high, it may suggest that in-person and online environments are growing evermore seamless for students. The virtual and physical campus are growing closer to one single social space, a phenomenon anticipated by early research on online social networking and college culture (Martínez Alemán \& Wartman, 2009). Another possibility is that with racism being omnipresent, students of color will experience online and offline racism in similar ways.

One possible reason for the greater impact of in-person racialized aggressions is that students of color curate their social media in ways in which they are not able to manage and regulate in-person campus experiences. In some ways, students seem to have more agency online. Online, students of color can "block" interactions with certain students, and can purposely restrict their online social network to exclude individuals and groups, as well as delete certain applications outright. On social media, students of color can ignore online posts, or simply choose not to look at these posts, behavior that is unworkable in daily campus living. Though certainly students of color have agency in face-to-face encounters on campus, and they can create proximal on-campus enclaves of vetted friendships, social media affords them greater control over and buffering against racialized aggressions.

The findings also suggest that as campus interactions with staff, faculty and administration improve in quality, students' positive perceptions of campus diversity climate increase. The model implies that as the quality of students' contact with academic advisors, faculty, student services staff, multicultural affairs staff, and other campus administrators increases, they interpret the campus racial climate more favorably.

The findings also point to students' of color ethnic identity development as a factor in their perceptions of a positive campus diversity climate. Findings show that as students' level of ethnic identity increases, so do their positive perceptions of the campus climate. 
The more advanced that students become in the development of their identity, it is then reasonable to suggest that their perceptions of the campus diversity climate may become more nuanced, more refined and mature, and that these perceptions may be more positive as a consequence.

\section{Implications and Conclusions}

This study adds to a gap in the literature that examines how students' of color experiences with racialized aggressions on social media and how such experiences with racism influence their perceptions of the campus climate. Our work is grounded in the work of Foucault (1980) who posited that discourse is constructed to exert power, and that discourse produces an effect on individuals. Minikel-Lacoque (2012) used that claim to make the case that racism is a discourse and points to social media as a discursive tool that has an impact on the recipient of that discourse, and our research supports this assertion. Adding to the qualitative research literature that explores social media and campus climate and culture (e.g., Eschmann, 2020; Gin et al., 2017), this quantitative analysis broadens and deepens our understanding of the role of social media as a discursive tool on the student of color campus experience. Bolstering the work Eschmann (2020) and Gin et al. (2017), our findings suggest that racialized aggressions on social media diminish students' of color positive perceptions of campus diversity climate when not accounting for in-person experiences with racism. Institutional actors will need to think about the influence of the online experiences for students, particularly regular discrimination, as well as the interactions that students are having in person on the campus. This is especially important in our current US context. While our data were collected in 2018-2019, these experiences are applicable in our current heightened environment of continued racial violence in our society, and the increase of activism on our campuses related to the Black Lives Matter movement, where our country often seems more divided than united. Students of color on our campuses, in particular student activists, may even be experiencing an increased number of racist incidents as a result of increased attention both on-line and in-person, and university administrators and faculty need to be able to provide support for these students, and provide educational opportunities for all students, so that students of color can experience a more positive campus climate.

Our findings add depth to the understanding of how in-person and social media-based racialized aggressions affect a student's perceptions of campus diversity climate. While in-person experiences with racism may overshadow racialized aggressions on social media, scholars and practitioners must be cognizant that online environments and experiences affect the outcomes of students of color (McCready et al., 2021; Rowan-Kenyon et al., 2021), especially as a result of the shift to more online interaction as a result of the COVID-19 pandemic. Additional scholarship is needed on the online experiences of students of color, including research that allows students of color to describe how encounters with racialized aggressions on social media influence their perceptions of campus diversity climates. Scholarship is also needed to understand how students of color curate their social media to minimize or mitigate their encounters with racialized aggressions.

The results provide evidence that students of color have increased positive perceptions of the diversity climates of their institutions as the quality of their interactions with faculty, staff, and administration improves. Faculty, staff, and administration must possess the competencies needed to support the learning and success of students of color, and institutional 
leaders, graduate program faculty, and other stakeholders should consider how these professionals are socialized to interact with an increasingly racially and ethnically diverse study body. In addition, our findings indicate that further examination of the relationship between the quality of students' contact with academic advisors, faculty, student services staff, multicultural affairs staff, and other campus administrators, their social knowledge reconstruction, and perceptions of campus climate are warranted.

\section{Appendix A}

See Table 5.

Table 5 Institutional characteristics (Total $N=771$ )

\begin{tabular}{llllll}
\hline & Institution A & Institution B & Institution C & Institution D & Institution E \\
\hline Number included in sample & 515 & 59 & 95 & 70 & 32 \\
\% of Sample & $66.8 \%$ & $7.7 \%$ & $12.3 \%$ & $9.1 \%$ & $4.2 \%$ \\
Geographic region & South & Northeast & Northeast & Northeast & Northeast \\
Institution type & Public & Private & Private & Private & Private \\
Religious affiliation & No & Yes & No & No & Yes \\
\% White & $48.9 \%$ & $82.5 \%$ & $54.6 \%$ & $51.0 \%$ & $66.0 \%$ \\
Response rate & $5.8 \%$ & $29 \%$ & $26.6 \%$ & $15.6 \%$ & $2.1 \%$ \\
\hline
\end{tabular}

Funding Funding for this work was provided by the NASPA Foundation, NASPA Region 1, and Boston College.

\section{References}

Atkinson, D., Morten, G., \& Sue, D. (1998). Counseling American minorities. McGraw Hill.

Bartlett, J., Reffin, J., Rumball, N., \& Williamson, S. (2014). Anti-social media. DEMOS.

Black, E. W., Mezzina, K., \& Thompson, L. A. (2016). Anonymous social media: Understanding the content and context of Yik Yak. Computers in Human Behavior, 57, 17-22. https://doi.org/10.1016/j.chb. 2015.11 .043

Bond, M., Kalaja, A., Markkanen, P. , Cazeca, D., Daniel, S., Tsurikova, L., \& Punnett, L. (2007, December). Expanding our understanding of the psychosocial work environment: A compendium of measures of discrimination, harassment and work-family issues. United National Institute for Occupational Safety and Health. https://www.cdc.gov/niosh/docs/2008-104/pdfs/2008-104.pdf

Bonifacio, L., Gushue, G., \& Mejia-Smith, B. (2018). Microaggressions and ethnic identity in the career development of Latina college students. The Counseling Psychologist, 46(4), 505-529. https://doi.org/ 10.1177/0011000018776909

Cabrera, A. F., Nora, A., Terenzini, P. T., Pascarella, E., \& Hagedorn, L. S. (1999). Campus racial climate and the adjustment of students to college. The Journal of Higher Education, 70(2), 134-160. https:// doi.org/10.1080/00221546.1999.11780759

Chavous, T., Richardson, B., Webb, F., Fonseca-Bolorin, G., \& Leath, S. (2017). Shifting contexts and shifting identities: Campus race-related experiences, racial identity, and academic motivation among Black students during the transition to college. Race and Socia Problems, 10, 1-18. https://doi.org/10.1007/ s12552-017-9218-9 
Clark, D. A., Spanierman, L. B., Reed, T. D., Soble, J. R., \& Cabana, S. (2011). Documenting Weblog expressions of racial microaggressions that target American Indians. Journal of Diversity in Higher Education, 4(1), 39-50. https://doi.org/10.1037/a0021762

Delgado, R., \& Stefancic, J. (2017). Critical race theory: An introduction (Vol. 20). NYU Press.

Eccles, J., Wong, C., \& Peck, S. (2006). Ethnicity as a social context for the development of African-American adolescents. Journal of School Psychology, 44(5), 407-426. https://doi.org/10.1016/j.jsp.2006.04. 001

Eschmann, R. (2020). Unmasking racism: Students of color and expressions of racism in online spaces. Social Problems, 67, 418-436. https://doi.org/10.1093/socpro/spz026

Eschmann, R., Groshek, J., Chanderdatt, R., Chang, K., \& Whyte, M. (2020). Making a microaggression: Using big data and qualitative analysis to map the reproduction and disruption of microaggressions through social media. Social MediaSociety, 6(4), 2056305120975716.

Fischer, M. J. (2007). Settling into campus life: Differences by race/ethnicity in college involvement and outcomes. The Journal of Higher Education, 78(2), 125-161. https://doi.org/10.1080/00221546.2007. 11780871

Foucault, M. (1980). Power/knowledge: Selected interviews and other writings, 1971-1977. Pantheon.

Foucault, M. (1975). Discipline and punish. A. Sheridan, Tr., Paris, FR, Gallimard.

Foucault, M. (1984). The Foucault reader. (P. Rabinow, Ed.) (First). Pantheon Books.

Franklin, J. D., Smith, W. A., \& Hung, M. (2014). Racial battle fatigue for Latina/o students: A quantitative perspective. Journal of Hispanic Higher Education, 13, 303-322. https://doi.org/10.1177/1538192714 540530

George Mwangi, C. A., Thelamour, B., Ezeofor, I., \& Carpenter, A. (2018a). "Black elephant in the room": Black students contextualizing campus racial climate within US racial climate. Journal of College Student Development, 59(4), 456-474. https://doi.org/10.1353/csd.2018.0042

George Mwangi, C. A., Bettencourt, G. M., \& Malaney, V. K. (2018b). Collegians creating (counter) space online: A critical discourse analysis of the I, Too, Am social media movement. Journal of Diversity in Higher Education, 11(2), 146-163. https://doi.org/10.1037/dhe0000054

Gin, K. J., Martínez-Alemán, A. M., Rowan-Kenyon, H. T., \& Hottell, D. (2017). Social media and racialized aggressions on campus. Journal of College Student Development, 58(2), 159-174. https://doi.org/ $10.1353 / \mathrm{csd} .2017 .0013$

Griffin, K. A., Cunningham, E. L., \& George Mwangi, C. A. (2016). Defining diversity: Ethnic differences in Black students' perceptions of racial climate. Journal of Diversity in Higher Education, 9(1), 34-49. https://doi.org/10.1037/a0039255

Harper, S.R., \& Hurtado, S. (2007). Nine themes in campus racial climates and implications for institutional transformation. In S.R. Harper, \& L. Patton (Eds.), Special Issue: Responding to the Realities of Race on Campus, (pp. 7-24). New Directions in Student Services, 120. Jossey Bass.

Harrell, S. P. (1997). The Racism and Life Experience Scales. (unpublished instrument). Pepperdine University Graduate School of Education and Psychology.

Hart, J., \& Fellabaum, J. (2008). Analyzing campus climate studies: Seeking to define and understand. Journal of Diversity in Higher Education, 1(4), 222-234. https://doi.org/10.1037/a0013627

Hurtado, S. (1992). The campus racial climate: Contexts for conflict. The Journal of Higher Education, 63(5), 539-569. https://doi.org/10.2307/1982093

Hurtado, S., Alvarado, A. R., \& Guillermo-Wann, C. (2015). Thinking about race: The salience of racial identity at two-and four-year colleges and the climate for diversity. The Journal of Higher Education, 86(1), 127-155. https://doi.org/10.1080/00221546.2015.11777359

Hurtado, S., \& Carter, D. F. (1997). Effects of college transition and perceptions of the campus racial climate on Latino college students' sense of belonging. Sociology of Education, 70(4), 324-345. https:// doi.org/10.2307/2673270

Hurtado, S., Carter, D. F., \& Spuler, A. (1996). Latino student transition to college: Assessing difficulties and factors in successful college adjustment. Research in Higher Education, 37(2), 135-157. https:// doi.org/10.1007/bf01730113

Hurtado, S., Clayton-Pedersen, A. R., Allen, W. R., \& Milem, J. F. (1998). Enhancing campus climates for racial/ethnic diversity: Educational policy and practice. The Review of Higher Education, 21(3), 279-302. https://doi.org/10.1353/rhe.1998.0003

Inkelas, K. K., Vogt, K. E., Longerbeam, S. D., Owen, J., \& Johnson, D. (2006). Measuring outcomes of living-learning programs: Examining college environments and student learning and development. The Journal of General Education, 55(1), 40-76. https://doi.org/10.1353/jge.2006.0017

Johnson, D. R., Wasserman, T. H., Yildirim, N., \& Yonai, B. A. (2014). Examining the effects of stress and campus climate on the persistence of students of color and White students: An application of 
Bean and Eaton's psychological model of retention. Research in Higher Education, 55(1), 75-100. https://doi.org/10.1007/s11162-013-9304-9

Keum, B. T., \& Miller, M. J. (2019). Measurement invariance of the perceived online racism scale across age and gender. Cyberpsychology Journal of Psychosocial Research on Cyberspace. https://doi.org/ $10.5817 / \mathrm{CP} 2018-3-3$

Khoo, J. (2017). Code words in political discourse. Philosophical Topics, 45(2), 33-64.

Kim, Y., \& Lundberg, C. A. (2016). A structural model of the relationship between student-faculty interaction and cognitive skills development among students. Research in Higher Education, 57(3), 288-309. https://doi.org/10.1007/s11162-015-9387-6

Lamerichs, N., Nguyen, D., Melguizo, M. C. P., Radojevic, R., \& Lange-Böhmer, A. (2018). Elite male bodies: The circulation of alt-right memes and the framing of politicians on social media. Participations, 15(1), 180-206.

Lau, L. (2003). Institutional factors affecting student retention. Education, 124(1), 126-136.

Lin, S., Salazar, T. R., \& Wu, S. (2019). Impact of academic experience and school climate of diversity on student satisfaction. Learning Environments Research, 22, 25-41. https://doi.org/10.1007/ s 10984-018-9265-1

Linares, L., \& Muñoz, S. (2011). Revisiting validation theory: Theoretical foundations, applications, and extensions. Enrollment Management Journal, 5(2), 12-33.

Lopez, G. (2016). Sneaky language today's politicians use to get away with racism and sexism. Retrieved from https://www.vox.com/2016/2/1/10889138/coded-language-thug-bossy

Martínez Alemán, A. M., \& Wartman, K. L. (2009). Online social networking on campus: Understanding what matters in student culture. Routledge/Francis Taylor Group.

Matamoros-Fernández, A., \& Farkas, J. (2021). Racism, hate speech, and social media: A systematic review and critique. Television \& New Media, 22(2), 205-224. https://doi.org/10.1177/1527476420 982230

Mayhew, M. J., Rockenbach, A. N., Bowman, N. A., Seifert, T. A., Wolniak, G. C., Pascarella, E. T., \& Terenzini, P. T. (2016). How college affects students (Vol 3) 21 st century evidence that higher education works. Jossey-Bass.

McCready, A. M., Rowan-Kenyon, H. T., Martínez Alemán, A. M., \& Barone, N. (2021). Students of color, mental health, and racialized aggressions on social media. Journal of Student Affairs Research and Practice, 58(2), 179-195. https://doi.org/10.1080/19496591.2020.1853555

Milem, J.F., Chang, M.J., \& Antonio, A.L. (2005). Making diversity work on campus: A research-based perspective. Association of American Colleges \& University.

Minikel-Lacocque, J. (2012). Racism, college, and the power of words: Racial microaggressions reconsidered. American Educational Research Journal, 50(3), 432-465. https://doi.org/10.3102/00028 31212468048

Moylan, C. A., Javorka, M., Maas, M. K., Meier, E., \& McCauley, H. L. (2021). Campus sexual assault climate: Toward an expanded definition and improved assessment. Psychology of Violence, 11(3), 296-306. https://doi.org/10.1037/vio0000382

Museus, S. D., \& Truong, K. A. (2013). Racism and sexism in cyberspace: Engaging stereotypes of Asian American women and men to facilitate student learning and development. About Campus, $18(4), 14-21$.

Nadal, K. (2008). Preventing racial, ethnic, gender, sexual minority, disability, and religious microaggressions: Recommendations for promoting positive mental health. Prevention in Counseling Psychology: Theory, Research, Practice and Training, 2(1), 22-27.

Nadal, K. L., Wong, Y., Sriken, J., Griffin, K., \& Fujii-Doe, W. (2015). Racial microaggressions and Asian Americans: An exploratory study on within-group differences and mental health. Asian American Journal of Psychology, 6(2), 136-144. https://doi.org/10.1037/a0038058

Nguyen, M. H., Chan, J., Nguyen, B., \& Teranishi, R. (2018). Beyond compositional diversity: Examining the campus climate. Journal of Diversity in Higher Education, 11(4), 484-501. https://doi.org/ $10.1037 /$ dhe0000071

Ortiz, A. M., \& Rhoads, R. A. (2000). Deconstructing Whiteness as part of a multicultural educational framework: From theory to practice. Journal of College Student Development, 41(1), 81-93.

Parker, E. T., III. (2021). Campus climate perceptions and sense of belonging for LGBTQ students: A Canadian case study. Journal of College Student Development, 62(2), 248-253. https://doi.org/10. 1353/csd.2021.0019

Parker, E. T., III., \& Trolian, T. L. (2020). Student perceptions of the climate for diversity: The role of student-faculty interactions. Journal of Diversity in Higher Education, 13(4), 333-344. https://doi. org/10.1037/dhe0000132 
Patton, L. D., Renn, K. A., Guido-DiBrito, F., \& Quaye, S. J. (2016). Student development in college: Theory, research, and practice (3rd ed). Jossey-Bass.

Peterson, M. W., \& Spencer, M. G. (1990). Understanding academic culture and climate. New Directions for Institutional Research, 1990(68), 3-18.

Pew Research Center. (2018). A majority of teens have experienced some form of cyberbullying. Retrieved from https://pewresearch-org-preprod.go-vip.co/internet/2018/09/27/a-majority-of-teenshave-experienced-some-form-of-cyberbullying/

Pew Research Center. (2021). The state of online harassment. Retrieved from https://www.pewresearch. org/internet/2021/01/13/the-state-of-online-harassment/

Phinney, J. (1992). The Multigroup Ethnic Identity Measure: A new scale for use with diverse groups. Journal of Adolescent Research, 7, 156-176. https://doi.org/10.1177/074355489272003

Phinney, J., \& Alipuria, L. (1990). Ethnic identity in college students from four ethnic groups. Journal of Adolescence, 13, 171-184.

Phinney, J. S., \& Ong, A. D. (2007). Conceptualization and measurement of ethnic identity: Current status and future directions. Journal of Counseling Psychology, 54(3), 271-281. https://doi.org/10. 1037/0022-0167.54.3.271

Rankin, S. R., \& Reason, R. D. (2005). Differing perceptions: How students of color and white students perceive campus climate for underrepresented groups. Journal of College Student Development, 46(1), 43-61. https://doi.org/10.1353/csd.2005.0008

Reid, L. D., \& Radhakrishnan, P. (2003). Race matters: The relation between race and general campus climate. Cultural Diversity and Ethnic Minority Psychology, 9(3), 263-275. https://doi.org/10. 1037/1099-9809.9.3.263

Rendon, L. I. (1994). Validating culturally diverse students: Toward a new model of student learning and development. National Center on Postsecondary Teaching, Learning, and Assessment.

Robertson, R. V., Bravo, A., \& Chaney, C. (2016). Racism and the experiences of Latina/o college students at a PWI (predominantly White institution). Critical Sociology, 42, 715-735. https://doi.org/ $10.1177 / 0896920514532664$

Rogers, K. (2016, September 21). Firestorm at 2 colleges after students share racially charged photos. The New York Times. Retrieved from: https://www.nytimes.com/2016/09/22/us/firestorms-at-2colleges-after-students-share-racially-charged-photos.html

Rowan-Kenyon, H. T., Martínez-Alemán, A. M., Gin, K. Blakeley, B., Gismondi, A., Lewis, J., McCready, A., Zepp, D., \& Knight, S. (2016). Social Media in higher education: ASHE Higher Education Report, Volume 42, Number 5. San Francisco: John Wiley.

Rowan-Kenyon, H. T., McCready, A. M., Martínez Alemán, A. M., \& Barone, N. (2021). Measuring racist aggressions on social media and the effects on U.S. college students of color: An instrument validation. Measurement and Evaluation in Counseling and Development, 54(3), 156-172. https://doi.org/ 10.1080/07481756.2020.1827437

Saha, K., Chandrasekharan, E., \& De Choudhury, M. (2019, June). Prevalence and psychological effects of hateful speech in online college communities. In Proceedings of the 10th ACM Conference on Web Science (pp. 255-264).

Sellers, R. M., \& Shelton, J. N. (2003). The role of racial identity in perceived racial discrimination. Journal of Personality and Social Psychology, 84(5), 1079-1092. https://doi.org/10.1037/00223514.84.5.1079

Smith, W. A., Allen, W. R., \& Danley, L. L. (2007). "Assume the position...you fit the description" Psychosocial experiences and racial battle fatigue among African American male college students. American Behavioral Scientist, 51(4), 551-578.

Smith, W., Yosso, T., \& Solórzano, D. (2006). Challenging racial battle fatigue on historically white campuses: A critical race examination of race-related stress. In R. D. Coates (Ed.), Covert racism: Theories, institutions and experiences (pp. 211-237). Brill Publishing.

Solórzano, D., Ceja, M., \& Yosso, T. (2000). Critical race theory, Racial microaggressions, and campus racial climate: The experiences of African American college students. Journal of Negro Education, $69(1 / 2), 60$.

Squire, M. (2019). Network, Text, and Image Analysis of Anti-Muslim Groups on Facebook. The Journal of Web Science, 7.

Stucky, B. D., Gottfredson, N. C., Panter, A. T., Daye, C. E., Allen, W. R., \& Wightman, L. F. (2011). An item factor analysis and item response theory-based revision of the everyday discrimination scale. Cultural Diversity and Ethnic Minority Psychology, 17(2), 175-185. https://doi.org/10.1037/a0023356

Suarez-Balcazar, Y., Orellana-Damacela, L., Portillo, N., \& Andrews-Guillen, C. (2003). Experiences of differential treatment among college students of color. Journal of Higher Education, 74(4), 428-444. 
Sue, D. W., Capodilupo, C. M., \& Holder, A. M. B. (2008). Racial microaggressions in the life experiences of Black Americans. Professional Psychology: Research and Practice, 39(3), 329-336. https://doi.org/10.1037/0735-7028.39.3.329

Sue, D. W., Capodilupo, C. M., Torino, G. C., Bucceri, J. M., Holder, A. M. B., Nadal, K. L., \& Esquilin, M. (2007). Racial microaggressions in everyday life: Implications for clinical practice. The American Psychologist, 62(4), 271-286. https://doi.org/10.1037/0003-066X.62.4.271

Sue, D. W., \& Sue, D. (2013). Counseling the culturally diverse: Theory \& practice (6th ed.). Wiley.

Torres, V. (2003). Influences on ethnic identity development of Latino college students in the first two years of college. Journal of College Student Development, 44(4), 532-547. https://doi.org/10.1353/csd.2003. 0044

Torres, V., \& Baxter Magolda, M. B. (2004). Reconstructing Latino identity: The influence of cognitive development on the ethnic identity process of Latino students. Journal of College Student Development, 45(3), 333-347. https://doi.org/10.1353/csd.2004.0043

Tynes, B. M., \& Markoe, S. L. (2010). The role of color-blind racial attitudes in reactions to racial discrimination on social network sites. Journal of Diversity in Higher Education, 3(1), 1-13.

Tynes, B. M., Rose, C. A., \& Markoe, S. L. (2013). Extending campus life to the Internet: Social media, discrimination, and perceptions of racial climate. Journal of Diversity in Higher Education, 6(2), $102-114$.

Tynes, B. M., Umaña-Taylor, A. J., Rose, C. A., Lin, J., \& Anderson, C. J. (2012). Online racial discrimination and the protective function of ethnic identity and self-esteem for African American adolescents. Developmental Psychology, 48(2), 343-435. https://doi.org/10.1037/a0027032

U.S. Office of Management and Budget. (2016). Review and possible limited revision of OMB's statistical policy directive on standards for maintaining, collecting, and presenting Federal data on race and ethnicity. Retrieved from https://www.federalregister.gov/documents/2016/09/30/2016-23672/standardsfor-maintaining-collecting-and-presenting-federal-data-on-race-and-ethnicity

Wells, A. V., \& Horn, C. (2015). The Asian American college experience at a diverse institution: Campus climate as a predictor of sense of belonging. Journal of Student Affairs Research and Practice, 52(2), 149-163. https://doi.org/10.1080/19496591.2015.1041867

Williams, D. R., Yu, Y., Jackson, J. S., \& Anderson, N. B. (1997). Racial differences in physical and mental health: Socio-economic status, stress and discrimination. Journal of Health Psychology, 2(3), 335351. https://doi.org/10.1177/135910539700200305

Yoon, E. (2011). Measuring ethnic identity in the ethnic identity scale and the multigroup ethnic identity measure-revised. Cultural Diversity \& Ethnic Minority Psychology, 17(2), 144-155. https://doi.org/10. $1037 / \mathrm{a} 0023361$

Yosso, T., Smith, W., Ceja, M., \& Solórzano, D. (2009). Critical race theory, racial microaggressions, and campus racial climate for Latina/o undergraduates. Harvard Educational Review, 79(4), 659-786.

Ziems, C., He, B., Soni, S., \& Kumar, S. (2020). Racism is a virus: Anti-asian hate and counterhate in social media during the covid-19 crisis. arXiv preprint arXiv:2005.12423.

Publisher's Note Springer Nature remains neutral with regard to jurisdictional claims in published maps and institutional affiliations. 